DOI 10.37882/2500-3682.2021.03.24

\title{
ПРЕДСТАВЛЕНИЕ ОБ УСПЕХЕ У ЛЮДЕЙ РАЗНЫХ ПОКОЛЕНИЙ
}

\section{PERCEPTION OF SUCCESS IN PEOPLE OF DIFFERENT GENERATIONS}

\section{Shukshina \\ O. Mizonova}

Summary: Ideas about success are formed under the influence of personal factors and social impact, since ideas about success are formed both in the individual and in the framework of social values. The idea of success depends on the age of the individual, since in accordance with the age, the individual puts forward demands on himself regarding achievements from the side of society, and in relation to the individual, a number of requirements are put forward regarding success.

Keywords: perceptions, success, values of generations, differences in perceptions of success.

\author{
Шукшина Людмила Викторовна \\ Д.ф.н., профессор, РЭУ им Г.В. Плеханова \\ liudmila.shukshina@yandex.ru \\ Мизонова Ольга Викторовна \\ К.ф.н., дочент, МГУ им. Н.П. Огарева \\ mizonovaov@mail.ru
}

Аннотация: Представления об успехе формируются под влиянием личностных факторов, и социального воздействия, так как представления об успехе сформированы как у личности, так и в рамках общественных ценностей. Представления об успехе зависят от возраста личности, так как в соответствии с возрастом, личность выдвигает к себе требования относительно достижений, со стороны социума, и по отношению к личности выдвигается ряд требований касательно успешности.

Ключевые слова: представления, успех, ценности поколений, различия в представлениях об успехе.
A ктуальность исследования представлений об успехе у людей разных поколений определяются тем, что от уровня успешности во многом зависит степень реализованности личности и её удовлетворенность собственной жизнью.

Феномен имеет множество разнообразных определений, каждый человек вкладывает в него свой смысл. В Толковом словаре русского языка отмечено, что существительное «успешность» образовано от прилагательного «успешный», то есть делающий что-либо с успехом. [1] Слово «успех» можно трактовать по-разному:

- достижение поставленной цели;

- общественное одобрение предпринимаемых действий;

- признание достоинств и достижений окружающими людьми.

«Успешность» в словаре русских синонимов определяется в схожем плане с «удачностью» и «благополучием». А «успех» трактуется как достижение, удача или признание[2].

Согласно А.С. Белкину, успех - это состояние удовлетворения, возникающее в случае достижения или схожего с желаемым, или более высокого результата в сравнении с предвосхищаемым. То есть человек достигает успеха в случае реализации намеченного плана или превосходства реальных результатов над ожидаемыми или желаемыми продуктами деятельности. Таким образом, в определениях, указанных выше, большую роль играют ожидания, и именно от них зависят и в соответствии с ними оцениваются результаты деятельности, ведь хорошо продуманный план действий более надёжный и более предсказуемый, чем неспланированные, спонтанные действия. И, в итоге, хорошо продуманная работа ведёт к значительному увеличению вероятности достижения успеха и желаемого результата, что приближает человека к более значительной, глобальной цели.

«Успех» же от "удачи» отличается целенаправленностью. Удача - скорее случайное явление, а успех - результат тщательно спланированной деятельности.

Н.А. Батурин придерживается аналогичной точки зрения и выделяет три основных значения понятия «успех»:

1. это оценка деятельности другого человека, который достиг высокого уровня результативности своей деятельности относительно других людей или относительно общественных ожиданий.

2. это субъективная оценка собственной деятельности, которая выражает высокую степень удовлетворения от достижения желаемой цели.

3. это психическое состояние, возникающее у человека в случае достижения важной цели.

Таким образом, успех - это обобщённый показатель собственных стараний и эффективности деятельности, который проявляется в общественном одобрении, и результатом которого служит возникновение чувства удовлетворённости собственным трудом и результатами.

Помимо понимания феномена успеха, очень важным для нас является рассмотрение особенностей людей разных поколений. Люди, живущие в разное время, росли и воспитывались абсолютно в разных условиях, и на формирование их личности, на формирование их мировоззрения и взглядов огромное влияние оказывали раз- 
ные внешние факторы времён их юности.

Довольно большой промежуток времени особое внимание уделялось разделению общества на различные группы по вертикальному принципу - на высшие, средние, низшие слои, разделение по полу и т.д., но с течением времени авторы начали уделять интерес так же разделению общества на возрастные категории, которые очень сильно различаются между собой.

Интерес в науке к проблематике поколений в конфликтологической парадигме возник в западной психологии и социологии к концу XX в. Приверженцами «теории конфликтов» являются М.В. Вдовина, Е.И. Иванова, Е.А. Смирнова, К. Лоренц, Ж. Мендель, и др., которые представляют конфликт поколений как естественный, всеохватывающий путь развития человеческого общества и детерминируется самой природой человека [2].

М.И. Постникова выделила следующие варианты определений понятия поколения:

1. люди, которые находятся приблизительно в одном и том же возрастном промежутке, возрасте;

2. совокупность людей, объединенных коллективной памятью на схожие исторические события и переживания;

3. люди, живущие в одинаковой среде, погруженные в схожие жизненные обстоятельства [10].

В данном исследовании мы придерживаемся социально-психологического принципа и рассматриваем поколение как группу людей, ограниченную рамками возраста, живущую в определенный исторический период и, как следствие, попадающую под влияние определенных социокультурных условий [11]

В условиях огромного темпа развития человечества у нас появляется возможность наблюдать за различиями в поведении и ценностях людей разных поколений, потому что срок жизни человека в сравнении с прошлыми столетиями увеличивается. Характер изменения и скорость общественной нестабильности влияет на общее снижение возраста одного поколения [12].

Теория поколений создана в 1991 году американскими учеными Нейлом Хоувом и Вильямом Штраусом. Они одновременно и независимо друг от друга изучали понятие «поколения». Их внимание привлек известный «конфликт поколений», который не связан с возрастными противоречиями. Адаптацию теории поколений для России в 2003-2004 году выполнила команда под руководством Евгении Шамис.

В основу данной теории лег тот факт, что системы ценностей у людей, выросших в разные исторические периоды, различаются. Это связано с тем, что ценности человека формируются не только в результате семейного воспитания, но и под влиянием общественных событий, всего контекста, в котором он находится в период взросления. В рамках адаптированой терминологии выделяют следующие периоды, связанные с соответствующими им поколениями XX в.: 1900-1923 гг. - величайшее поколение, 1923-1943 гг. - «молчаливое поколение», 1943-1963 гг. - «беби-бумеры», 1963-1983 гг. - «поколение X», 1983-2000 гг. - «поколение Y», 2001 г. и далее - «поколение Z». Теория Хоува и Штраусса (и ее российская адаптация) являются научно-популярным концептом. Существуют и иные, менее популярные классификации поколений (Дубин, Гражданкин и пр.).

Рассмотрим более подробно изучаемые нами поколения. Поколение беби-бумеров (1943-1963). События, которые оказали огромное влияние на формирование ценностей людей данного поколения это: победа в Великой Отечественной войне, советская «оттепель», покорение космоса, единые стандарты обучения в школах и гарантированность медицинского обслуживания. Наименование поколение получило из-за послевоенного всплеска рождаемости. Эти люди - оптимисты, командные, коллективные люди.

Далее нами рассматривается поколение X, или Неизвестное поколение (1963-1984). Их родители считали, что чем лучше ребенок научится справляться с трудностями, тем проще ему будет жить. Поэтому они не облегчали жизнь своим детям. Представители данного поколения делают выводы, основываясь на собственном опыте, но при этом сильно ориентированы на мнение близких людей, семьи. Во время взросления людей поколения X была закрытость страны, застой, холодная война, появление наркотиков, начало перестройки и много разводов, из-за чего у некоторых людей стали занимать менее устойчивое положение семейные ценности. Они больше индивидуалисты, но при этом в жизни для них очень важны самые близкие люди.

Поколение Y, или поколение Миллениум, Next (1984-2000). В систему ценностей этих людей включены понятия «мораль», «ответственность», но при этом они большинстве наивны и умеют подчиняться. На время их взросления пришлись распад СССР, военные конфликты, бурное развитие коммуникаций, цифровых технологий. Остро встала проблема зависимостей. Важный аспект глобализация. Из-за того, что внешняя среда вокруг них менялась очень быстро, им стало присуще неверие в отдаленную перспективу.

Проводимое нами исследование опирается именно на вышеупомянутую концепцию. И исходя из этой периодизации, мы выявляем взаимосвязь между принадлежностью к поколению и представлением об успехе у представителей данного поколения. 
В исследовании приняли участие 54 испытуемых, которые являются представителями разных поколений. 13 испытуемых принадлежат к поколению 1943-1963-х гг. «беби-бумеры», 20 испытуемых принадлежат к поколению 1963-1983-х гг. - «поколение Х», и 21 испытуемый принадлежит к 1983-2000-м гг. - «поколение Ү». Средний возраст представителей поколения «беби-бумеров» составил 69,5 лет. Диапазон их возраста варьировался от 63 до 79 лет. Испытуемые, представляющие поколение «Х», находились в возрасте от 42 до 55 лет. Их средний возраст составил 47,4. Средний возраст представителей поколения «У» составил 24,6 лет. Их возраст был равен от 19 до 34 лет.

В качестве методик исследования использовались:

1. Методика определения ценностей Шварца;

2. Шкала общей самоэффективности (Р. Шварцер, М. Ерусалем);

3. Авторская анкета.

Первая методика - методика определения ценностей Шварца (1) - на диагностику ценностной сферы позволила определить первостепенные ценности представителей каждого поколения. Методика была разделена на две части. В первой части необходимо было из списка из тридцати ценностей сначала выбрать наиболее значимую для человека ценность, а затем наименее значимую. И после этого нужно было оценить оставшиеся ценности в зависимости от их значимости для человека по указанной нами шкале от -1 до 7. Но крайние показатели -1 и 7 лучше всё же использовать как можно меньше.

Вторая часть методики содержала вопросы с 31 по 57, т.е. 27 вопросов, и в ней требовалось оценить каждый вопрос по такой же шкале от -1 до 7, с тем же условием изначального выбора наиболее и наименее значимых жизненных ценностей с оценкой 7 и -1 соответственно.

Вторая методика - шкала общей самоэффективности. Она включает 10 вопросов, которые позволили определить уровень достижений личности. А, как нам известно, именно ценности определяют направленность личности человека, его успешность и стремления. И, таким образом, мы определили успешность личности в достижении поставленных ею целей.

И третья методика - авторская анкета - состоит из основных ценностей, которые нужно было проранжировать в виде цифр от 1 до 8 от наиболее значимой и ведущей в жизни до наименее значимой на пути к достижению успеха. Где первая цифра означала наибольшую значимость ценности, её преобладание в жизни человека, а последняя цифра представляла наименьшую ценность. Таким образом, каждый испытуемый определил для себя и сопоставил важность каждой из 8 жизненных ценностей.
После проведения методик, мы перевели сырые баллы в стобалльную систему для удобства в обработке и восприятии информации. А затем провели корреляционный анализ между основными ценностями и принадлежностью к поколению.

В результате психодиагностического обследования испытуемых по методикам: «Методика определения ценностей Шварца»; «Шкала общей самоэффективности» (р. Шварцер, м. Ерусалем) и авторская анкета были выявлены представления об успешности, а так же наиболее важные ценности представителей разных поколений.

Исходя из полученных и обработанных данных, определяем взаимосвязь между принадлежностью к определённому поколению и представлениями об успешности. Данные представлены на диаграмме 1 (Рис. 1).

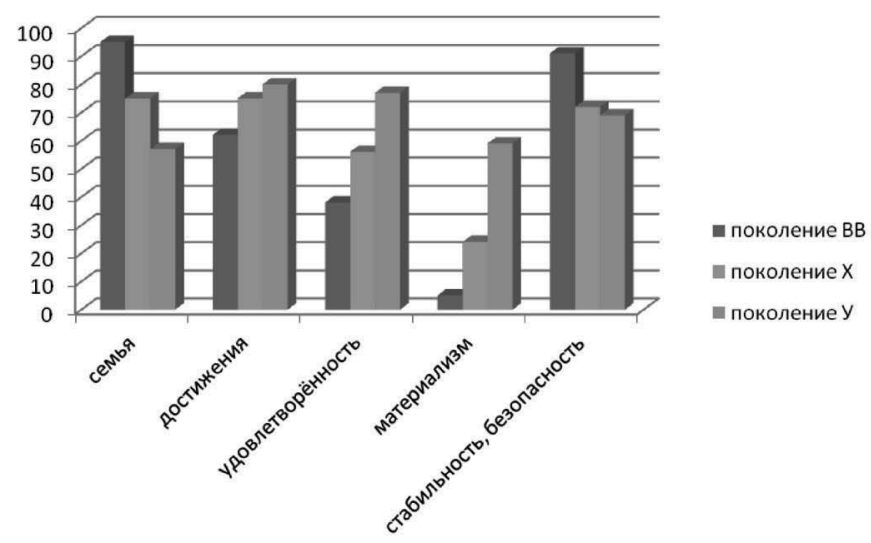

Рис. 1. Взаимосвязь между принадлежностью к определённому поколению и представлениями об успешности

Для определения наличия или отсутствия взаимосвязи между принадлежностью к определённому поколению и представлением об успехе, произведём расчет коэффициента корреляции Пирсона.

Обозначим ценность семьи, как $A$, стабильность - B, достижения - C, гедонизм - D, материализм - E, и возраст - F.

1. Вычисляем сумму каждого значения интересующих нас показателей:

$$
\begin{aligned}
& A=3643 \\
& B=4066 \\
& C=4096 \\
& D=3229 \\
& E=1786 \\
& F=2368
\end{aligned}
$$

2. Вычисляем среднее арифметическое по каждому показателю:

$$
\begin{aligned}
& A=67,5 \\
& B=75,3 \\
& C=75,9 \\
& D=59,8 \\
& E=33,1
\end{aligned}
$$




\section{$F=43,9$}

3. Вычисляем для каждого испытуемого отклонения от среднего арифметического (см. таблица 1).

Таблица 1

Отклонения от среднего арифметического

\begin{tabular}{|c|c|c|c|c|c|c|}
\multicolumn{1}{l|}{} & A & D & C & B & E & F \\
\hline $\mathbf{1}$ & 59 & 50 & 4 & -22 & 19 & $-19,1$ \\
\hline $\mathbf{2}$ & -7 & -21 & -6 & -16 & 19 & $-24,1$ \\
\hline $\mathbf{3}$ & -15 & 22 & 12 & -13 & 33 & $-23,1$ \\
\hline $\mathbf{4}$ & -24 & 26 & 1 & -13 & 33 & $-26,1$ \\
\hline $\mathbf{5}$ & -13 & 41 & 15 & -13 & 33 & $-24,1$ \\
\hline $\mathbf{6}$ & -21 & 26 & 4 & -22 & 33 & $-25,1$ \\
\hline $\mathbf{7}$ & -15 & 17 & 1 & -8 & 19 & $-28,1$ \\
\hline $\mathbf{8}$ & 42 & 31 & 8 & -22 & 19 & $-25,1$ \\
\hline $\mathbf{9}$ & -7 & 36 & 19 & -8 & 19 & $-32,1$ \\
\hline $\mathbf{1 0}$ & -15 & 41 & 8 & -13 & 33 & $-35,1$ \\
\hline $\mathbf{1 1}$ & -7 & 3 & 1 & -22 & 33 & $-30,1$ \\
\hline $\mathbf{1 2}$ & -13 & 17 & 8 & -16 & 33 & $-19,1$ \\
\hline $\mathbf{1 3}$ & -24 & -7 & 1 & -19 & 33 & $-21,1$ \\
\hline $\mathbf{1 4}$ & 16 & 36 & 8 & -19 & 19 & 0,9 \\
\hline $\mathbf{1 5}$ & -13 & 3 & -6 & -5 & 5 & $-1,1$ \\
\hline $\mathbf{1 6}$ & -10 & -16 & -6 & 12 & -10 & $-6,1$ \\
\hline $\mathbf{1 7}$ & -21 & 3 & 4 & -2 & 5 & $-0,1$ \\
\hline $\mathbf{1 8}$ & -21 & 12 & -3 & 4 & 19 & $-1,1$ \\
\hline $\mathbf{1 9}$ & -1 & -2 & -3 & 10 & 19 & $-1,1$ \\
\hline $\mathbf{2 0}$ & -13 & 17 & -6 & 4 & 33 & 1,9 \\
\hline $\mathbf{2 1}$ & -10 & 3 & -3 & 7 & -10 & $-0,1$ \\
\hline $\mathbf{2 2}$ & -4 & 3 & 1 & 4 & 5 & $-9,1$ \\
\hline $\mathbf{2 3}$ & -1 & -2 & 4 & 12 & 5 & $-2,1$ \\
\hline $\mathbf{2 4}$ & 16 & 7 & -10 & 4 & 19 & $-11,1$ \\
\hline $\mathbf{2 5}$ & -4 & -7 & -13 & 10 & 5 & $-6,1$ \\
\hline $\mathbf{2 6}$ & -13 & -7 & 4 & -8 & -10 & $-4,1$ \\
\hline $\mathbf{2 7}$ & -15 & 7 & 8 & -8 & 5 & $-2,1$ \\
\hline $\mathbf{2 8}$ & -21 & -2 & 12 & 7 & 19 & $-1,1$ \\
\hline $\mathbf{2 9}$ & 8 & 7 & 12 & 7 & 19 & $-1,1$ \\
\hline $\mathbf{3 0}$ & -13 & 17 & 8 & 4 & 33 & $-7,1$ \\
\hline $\mathbf{3 1}$ & -10 & -2 & 8 & 12 & -10 & $-9,1$ \\
\hline $\mathbf{3 2}$ & -13 & 3 & 1 & 10 & 5 & $-11,1$ \\
\hline $\mathbf{3 3}$ & -18 & -2 & -6 & 10 & 5 & 0,9 \\
\hline $\mathbf{3 4}$ & 16 & -12 & 1 & 27 & -10 & 21,9 \\
\hline $\mathbf{3 5}$ & 16 & -26 & 19 & -10 & -24 & 19,9 \\
\hline $\mathbf{3 6}$ & 13 & -12 & -13 & 1 & -10 & 23,9 \\
\hline $\mathbf{3 7}$ & 10 & -31 & -10 & 10 & -38 & 24,9 \\
\hline $\mathbf{3 8}$ & 13 & -16 & -6 & -8 & 5 & 22,9 \\
\hline $\mathbf{3 9}$ & 10 & -7 & 8 & 10 & -53 & 22,9 \\
\hline $\mathbf{4 0}$ & 8 & -12 & -6 & 10 & 5 & 21,9 \\
\hline $\mathbf{4 1}$ & 16 & -21 & 1 & 12 & -10 & 10,9 \\
\hline & & & & & & \\
\hline
\end{tabular}

\begin{tabular}{|c|c|c|c|c|c|c|}
\multicolumn{1}{l|}{} & A & D & C & B & E & F \\
\hline $\mathbf{4 2}$ & 8 & -21 & -24 & 7 & -38 & 9,9 \\
\hline $\mathbf{4 3}$ & -13 & -16 & -6 & 10 & -53 & 13,9 \\
\hline $\mathbf{4 4}$ & 13 & -12 & -6 & 18 & -24 & 15,9 \\
\hline $\mathbf{4 5}$ & 19 & -21 & 1 & 10 & -38 & 14,9 \\
\hline $\mathbf{4 6}$ & 5 & -12 & -3 & 7 & -10 & 14,9 \\
\hline $\mathbf{4 7}$ & 2 & -21 & -3 & 15 & -10 & 22,9 \\
\hline $\mathbf{4 8}$ & 13 & -16 & 1 & 1 & 5 & 22,9 \\
\hline $\mathbf{4 9}$ & 8 & -21 & -13 & -5 & -67 & 14,9 \\
\hline $\mathbf{5 0}$ & 13 & -40 & -3 & 4 & -53 & 23,9 \\
\hline $\mathbf{5 1}$ & 16 & -16 & -10 & 1 & -24 & 23,9 \\
\hline $\mathbf{5 2}$ & 2 & -2 & -6 & 10 & -10 & 22,9 \\
\hline $\mathbf{5 3}$ & 19 & -7 & -3 & 4 & -38 & 18,9 \\
\hline $\mathbf{5 4}$ & 13 & -16 & -6 & 1 & -38 & 15,9 \\
\hline
\end{tabular}

Подставляем полученные значения в формулу коэффициента корреляции Пирсона и получаем следующие значения:

1. $r_{\text {af }}=6657 / \sqrt{ } 262076462,07$

$$
r_{\text {af }}=0,41
$$

2. $r_{b f}=7191 / \sqrt{ } 373933214,74$

$r_{b f}=0,37$

3. $r_{c f}=-3543 / \sqrt{ } 67741170,26$

$r_{\mathrm{cf}}=-0,43$

4. $r_{d f}=-11336 / \sqrt{ } 131022932,36$

$r_{d f}=-0,9$

5. $r_{\text {ef }}=-19264 / \sqrt{ } 666551279,15$

$r_{\text {ef }}=-0,75$

Оценивая взаимосвязь между принадлежностью к определенному поколению и представлением об успехе в соответствии с таблицей значений величин коэффициента корреляции.

Таким образом, между возрастом и представлением об успехе, как о семейном благополучии присутствует слабая по силе взаимосвязь. Её слабость связана с тем, что для представителей всех поколений важны семейные ценности, но для более старших поколений они важнее, чем для более молодых.

Между принадлежностью к определённому поколению и представлением об успехе, как о стабильности и безопасности присутствует слабая по силе взаимосвязь. Это может быть обусловлено тем, что данные потребности являются базовыми для человека, поэтому присутствуют в большой степени у всех возрастных групп, но всё же наиболее сильно проявлены данные потребности у представителей более старшего поколения, пережившего ужасный послевоенный период восстановления страны, и знающего ценность стабильности и безопасности.

Между возрастом и представлением об успехе, как о 
достижении желаемой цели присутствует слабая по силе отрицательная корреляция, которая обозначает, что чем к более младшему поколению принадлежит человек, тем более ему свойственно представлять успех, как достижение поставленной цели, и наоборот.

Так же, между возрастом и представлением об успехе, как о наслаждении жизнью присутствует очень сильная отрицательная корреляция. Это означает, что чем больше человек относится к более старшему поколению, тем ему менее свойственно считать успех, как способность получения удовольствия от жизни, и наоборот.

И последний показатель успеха - материальное благополучие. Между принадлежностью к поколению и представлением об успехе, как о материальном благополучии присутствует высокая отрицательная по силе корреляция. Это связано с тем, что для представителей более младшего поколения важно обеспечить своё материальное благополучие, обеспечить для себя беззаботную старость, а так же насладиться жизнь, то есть побывать в различных интересных местах, попробовать что-то новое. Всё это требует материальных затрат. А представители более старшего поколения нацелены на заботу о семье, стабильность, и для них уже не настолько сильно важна материальная сторона жизни.
После проведения эмпирического исследования мы выясни, что представителям самого старшего поколения 1943-1963-х гг. - «беби-бумерам», свойственно понимать под успехом семейное благополучие и стабильность. Представители 1963-1983-х гг. - «поколение X», понимают под успехом семейное благополучие и достижение жизненных целей. А представители поколения 1983-2000-х гг. - «поколение Ү», считают, что успех - это материальное благополучие, удовлетворённость и наслаждение жизнью, а так же достижение целей.

Данные выводы вполне предсказуемы и обоснованы, потому что представители более младшего поколения амбициозны, полны сил для свершений и достижений, а так же стремятся узнать много нового и обеспечиться для себя стабильное будущее, для чего требуется материальное благополучие. Для представителей поколения У актуальным является осознавание своих жизненных достижений. Они уже начинают готовиться пенсии, у них появляются внуки, и жизненный ракурс смещается на семейные ценности. Представители же самого старшего поколения в большинстве своём уже не работают, заботятся о внуках. Для них самым важным является благополучие семьи.

Таким образом, проведенное исследование позволило нам выявить различия в представлениях об успехе у представителей разных поколений.

\section{ЛИТЕРАТУРА}

1. Абрамова. Н. Словарь русских синонимов и сходных по смыслу выражений - М.: Русские словари. - 1999.

2. Батурин Н.А. Психология успеха и неудачи: учеб. пособие. - Челябинск: ЮУрГУ. - 1999. - 99 с.

3. Дементий Л.И. Ответственность как ресурс личности - М.: ИнформЗнание. - 2005. -188 с.

4. Дергунов Т. Практическое пособие начинающего руководителя / -М: Манн, Иванов и Фербер. - 2015. - 205 с.

5. Дружилов С.А. Психология профессионализма: Инженерно-психологический подход. - Харьков: Издательский дом «Гуманитарный центр». - 2011. - 296 с.

6. Лабунская В.А. Психология успешного поведения личности / В.А. Лабунская, О.И. Ефремова // Социальная психология личности в вопросах и ответах : учеб. пособие для вузов / под ред. В.А. Лабунской. - М.: Гардарики. - 1999. - 397 с

7. Лабунская В.А. «Социальная психология личности в вопросах и ответах» М., 1999.

8. Леонтьев А.Н. Деятельность, сознание, личность. М. - 1975.

9. Манухина С. Эмпирический анализ мотивации достижения как структурного образования. М. - 2002.

10. Постникова М.И. Межпоколенные отношения в контексте культурно исторической концепции / М.И. Постникова // Мир науки, культуры и образования. $-2010 .-$ № 4 (23). - С. 125-128.

11. Постникова М.И. Поколение и проблематика / М.И. Постникова, И.А. Шевчук // Мир науки, культуры и образования. - 2007. - № 6. - С. $87-91$.

12. Сочивко Н.В. Проблема изучения поколений в психологии / Н. В. Сочивко // Культур.-ист. психология. - 2011. - Т.11, № 2. - С. 100-107.

13. Толковый словарь русского языка: В 4т. / под ред. Д.Н. Ушакова. - М. - 2000.

14. Фрейджер Р.,Фейдимен Д. «Личность. Теории, упражнения, эксперименты» - СПб.: Прайм-ЕВРОЗНАК, 2004. - 608 c.

15. Хьелл Л., Зиглер Д. Теории личности. СПб.: Издательство «Питер». - 1999. - 608 с.

16. Гиоева Е.П. Феномен успеха в воззрениях классиков психоанализа и гештальтпсихологии [Электронный ресурс] // Современные проблемы науки и образования. - 2014. - № 6.; URL: http://www.science-education.ru/ru/article/view?id=15797 (дата обращения: 05.01.2020). 